\section{Alcohol and cor pulmonale in chronic bronchitis and emphysema}

\author{
Ronald Jalleh, Michael F Fitzpatrick, \\ Mohammed A Jan, William MacNee, \\ Neil J Douglas
}

Respiratory Medicine Unit, Department of Medicine (RIE), City Hospital, Edinburgh EH10 5SB Ronald Jalleh, research fellow Michael F Fitzpatrick, lecturer Mohammed A Jan, research fellow

William MacNee, senior lecturer

Neil J Douglas, reader

Correspondence to: Dr Douglas.

$B M 7$ 1993;306:374 and peripheral oedema in patiets with bronchitis.

\section{Patients, methods, and results}

The development of peripheral oedema is a major determinant of a poor prognosis in patients with chronic bronchitis and emphysema' and, when unexplained by other medical conditions, is called cor pulmonale. Chan et al found that raised alcohol consumption was associated with hypercapnic respiratory failure in bronchitis patients. ${ }^{2}$ As oedematous patients with bronchitis tend to be hypercapnic, we have studied the relation between alcohol consumption

We studied 73 patients ( 39 women and 34 men with a mean age of 68 (SEM 1) years) with severe chronic bronchitis and emphysema (forced expiratory volume in one second $<1.51$ ). None of the patients had liver, renal, or ischaemic heart disease; systemic hypertension; or hypoproteinaemia. All had been clinically stable for over three weeks.

Lifetime histories of alcohol consumption and smoking were taken from each patient with a reproducible structured interview technique that used key life events (for example, job changes, marriage, childbirth) to help patients remember. ${ }^{2}$ The presence or absence of dependent oedema was noted and records reviewed for previous documentation of oedema. We measured the patients' arterial blood gas tensions, forced expiratory volume, and forced vital capacity. Within the year before the interview 27 patients had had pulmonary arterial pressures measured directly and 23 had had total lung capacity (helium dilution) and gas transfer measured.

Unpaired Student's $t$ tests and $\chi^{2}$ tests were used to compare data between groups. Logistic regression analysis with forward stepwise entry of variables was used to assess the relative contributions of different factors to the development of oedema. ${ }^{3}$ For this analysis, average alcohol consumption was graded into four bands: $0,1-10,11-30$, and $>30$ units/week. Odds ratios were also calculated for the different factors.

Comparison of bronchitic patients with and without oedema. Figures are means (SD)

\begin{tabular}{|c|c|c|}
\hline & With oedema & No oedema \\
\hline No and sex & $20 \mathrm{M}, 26 \mathrm{~F}$ & $14 \mathrm{M}, 13 \mathrm{~F}$ \\
\hline Age (years) & $69(6)$ & $67(5)$ \\
\hline Body mass index $\left(\mathrm{kg} / \mathrm{m}^{2}\right)$ & $24(6)$ & $22(8)$ \\
\hline $\mathrm{FEV}_{1}(\%$ predicted $)$ & $31(12)$ & $28(12)$ \\
\hline Total lung capacity (1) & $5 \cdot 7(1 \cdot 7)$ & $6 \cdot 9(1 \cdot 1)$ \\
\hline $\mathrm{TLCO}_{\mathrm{Lmol} / \mathrm{m})}$ & $3 \cdot 6(1 \cdot 4)$ & $2 \cdot 6(1.0)$ \\
\hline Arterial $\mathrm{PO}_{2}(\mathrm{kPa})$ & $7 \cdot 1(1 \cdot 3)$ & $7.5(1.3)$ \\
\hline Arterial $\mathrm{PCO}_{2}(\mathrm{kPa})$ & $6.7(0.9)$ & $6.5(0.8)$ \\
\hline Pulmonary arterial pressure $(\mathrm{mm} \mathrm{Hg})$ & $24(8)$ & $19(7)$ \\
\hline Cigarettes smoked (pack years) & $48(25)$ & $42(9)$ \\
\hline \multicolumn{3}{|l|}{$\begin{array}{l}\text { Alcohol consumption: } \\
\text { S }\end{array}$} \\
\hline Each week (units) ${ }^{\star}$ & $12(19)$ & $4(7)$ \\
\hline Lifetime (units) & $25000(46000)$ & $8000(14000)$ \\
\hline \multicolumn{3}{|l|}{ Plasma protein $(\mathrm{g} / \mathrm{l})$ : } \\
\hline Total protein & $73(6)$ & $70(5)$ \\
\hline Albumin & $41(4)$ & $40(4)$ \\
\hline
\end{tabular}

$\mathrm{FEV}_{1}=$ Forced expiratory volume in one second. $\mathrm{TLCO}_{\mathrm{LCO}}$ Carbon monoxide transfer factor.

*Mean weekly alcohol consumption since age 15 .
The oedematous patients had similar lung function, smoking histories, and plasma protein concentrations to the patients without oedema. The oedematous patients tended, however, to be more hypoxaemic, with higher arterial $\mathrm{PCO}_{2}$, and to have higher pulmonary arterial pressure, higher alcohol consumption, and higher body mass index, than those without oedema (table).

The only variables significantly related to the development of peripheral oedema on regression analysis with high alcohol consumption (odds ratio $4 \cdot 1$ (95\% confidence interval $1 \cdot 6$ to $7 \cdot 1$ ), $p=0 \cdot 002$ ), being female $(10.2(1.7$ to $59 \cdot 1), \mathrm{p}=0.01)$, and high body mass index $(1.12(1.00$ to 1.25$), p=0.04)$. There was no significant correlation between arterial $\mathrm{PCO}_{2}$ and alcohol consumption $(r<0 \cdot 14)$.

\section{Comment}

This study shows that alcohol consumption is an important independent predictor of peripheral oedema in patients with chronic bronchitis and emphysema. How alcohol predisposes to peripheral oedema is not clear, but it is not through hypoproteinaemia.

The patients with oedema tended to have higher pulmonary arterial pressures than those without $(p=0 \cdot 12)$, and alcohol may possibly intensify the effect of hypoxaemia.on the pulmonary circulation to increase arterial pressure. Alcohol may also contribute to nocturnal hypoxaemia by causing narrowing of the upper airways. ${ }^{2}$ Another possible explanation is that alcohol impairs renal sodium excretion ${ }^{4}$; the resulting sodium retention could contribute to the development of peripheral oedema.

Obesity can increase nocturnal hypoxaemia, and we found a positive relation between body mass index and the presence of oedema. We also found that peripheral oedema was more common among our female patients, but we did not identify the cause of this effect.

Unlike Chan et al, ${ }^{2}$ we found no significant relation between alcohol consumption and arterial $\mathrm{PCO}_{2}$. But the alcohol consumption of Chan et al's hypercapnic group averaged 124 units/week, which is much higher than that of our patients, whose consumption was similar to that of the population in Edinburgh studied by Chick et al..$^{5}$

We thank Dr R A Elton, senior lecturer in the Medical Statistics Unit, University of Edinburgh, for his help with analysing the data.

1 France AJ, Prescott RJ, Biernacki W, Muir AL, MacNee W. Does righ ventricular function predict survival in patients with chronic obstructive lung disease? Thorax 1988;43:621-6

2 Chan CS, Bye PTP, Woolcock AJ, Sullivan CE. Eucapnia and hypercapnia in patients with chronic airflow limitation: the role of the upper airway. Am Rev Respir Dis 1990;141:861-5.

3 SPSS advanced statistics user's guide. Chicago: SPSS, 1990:64-9.

4 Musabayane CT, Brimble MJ, Balment RJ. Renal sodium retention and vasopressin induced kaliuresis in ethanol anaesthetised rats. Acta Endocrinol vasopressin induci

5 Chick J, Duffy JC, Lloyd G, Ritson EB. Medical admissions in men: the risk among drinkers. Lancet 1986;ii: 1380-3.

(Accepted 25 November 1992)

\section{Correction}

Torsades de pointes after terfenadine-itraconazole interaction

An editorial error occurred in this drug point by $S$ PohjolaSintonen and colleagues (16 January, $p$ 186). In the fourth sentence of the fourth paragraph the highest level of terfenadine's acid metabolite is given as $160 \mathrm{pg} / \mathrm{l}$; this should read $160 \mu \mathrm{g} / \mathrm{l}$. 